Kelola

Jurnal Manajemen Pendidikan

Magister Manajemen Pendidikan

ISSN 2443-0544

FKIP Universitas Kristen Satya Wacana

Volume: 3, No. 2, Juli-Desember 2016

jurnalkelola@gmail.com

Halaman: 164-177

\title{
STRATEGI BERSAING UNTUK MENINGKATKAN \\ DAYA SAING SEKOLAH TINGGI TEOLOGIA DI UNGARAN
}

\author{
I Putu Ayub Darmawan \\ Program Studi Pendidikan Agama Kristen \\ Sekolah Tinggi Teologi Simpson Ungaran \\ putuayub@sttsimpson.ac.id \\ Sutriyono \\ Program Pascasarjana Magister Manajemen Pendidikan \\ FKIP-Universitas Kristen Satya Wacana \\ sutriyono@staff.uksw.edu
}

\begin{abstract}
This study aimed to design a competitive strategy to improve the competitiveness of STT Simpson. This study was a research and development. The data were collected through observation, FGD (Focus Group Discussion) and interviews. Competitive strategies of STT Simpson are 1) Differentiation strategy: STT Simpson can offer theological education class in the evening to optimize the facilities owned for the churches in Ungaran and its surrounding; 2) Cost advantage strategy: STT Simpson has an advantage in some types of costs but STT Simpson still have to adjust the tuition course to prevent the gap with another STT and keep maintaining its competitiveness; 3) Focus strategy: STT Simpson perform its marketing by focusing on youth of the church around GKII; and 4) Marketing communication strategy with various forms of marketing communications utilizing the technologies esvolving by offering characteristics possessed.
\end{abstract}

Keywords: Competitive Strategy, Differentation Strategy, Cost Advantage Strategy, Focus Strategy. Marketing Communiction Strategy

\begin{abstract}
ABSTRAK
PENDAHULUAN

Pendidikan merupakan salah satu komponen penting untuk menyediakan sumber daya manusia (SDM). Ketersediaan SDM yang berkualitas dapat dipenuhi melalui pendidikan yang berkualitas, apabila kualitas pendidikan kurang baik maka akan menghasilkan SDM yang kurang baik juga. Penyedia SDM dalam bidang keagamaan adalah sekolah dengan pendidikan keagamaan. Kebutuhan SDM dalam agama Kristen untuk kepentingan gereja dan ketersediaan guru agama Kristen dihasilkan melalui pendidikan Teologi dan PAK pada universitas Kristen dan Sekolah Tinggi Teologi/Agama Kristen (STT/AK). Perguruan tinggi tersebut menyiapkan SDM yang berperan sebagai pengawal moral bangsa.
\end{abstract}


Pendidikan teologi adalah pendidikan keagamaan Kristen yang diselengarakan dalam beberapa jalur pendidikan yaitu pendidikan formal, nonformal, dan informal. Jalur pendidikan formal diselenggarakan pada jenjang pendidikan dasar (Sekolah Dasar Teologi Kristen dan Sekolah Menengah Pertama Teologi Kristen), pendidikan menengah (Sekolah Menengah Agama Kristen dan Sekolah Menengah Teologi Kristen yang terdiri atas tiga tingkat), dan pendidikan tinggi. Pendidikan tinggi dapat berbentuk STAK dan STT atau bentuk lain yang sejenis (PP No. 55 tahun 2007). Penyelenggaraan STAK, STT atau bentuk lain yang sejenis dapat diselenggarakan oleh Pemerintah, pemerintah daerah dan/atau masyarakat (gereja dan atau lembaga keagamaan Kristen). Pembinaan Pendidikan keagamaan Kristen jalur pendidikan formal dilakukan oleh Menteri Agama atau pihak yang ditunjuk (PP No. 55 tahun 2007).

Pendidikan ini diselenggarakan untuk menyiapkan tenaga pengerja yang bermutu dan teruji dalam spiritualitas dan moral Kristiani untuk memenuhi kebutuhan gereja, para gereja maupun melayani masyarakat pada umumnya. Dalam perkembangannya pendidikan teologi tidak hanya menyelenggarakan Prodi Teologi melainkan juga Prodi Pendidikan Agama Kristen untuk memenuhi kebutuhan guru agama Kristen.

Hingga bulan Mei 2014 jumlah penyelenggara Program Studi (Prodi) S1 Teologi/ Kependetaan dan PAK relatif banyak, sebagaimana tergambar dalam Tabel 1. Data tersebut belum mencakup STT/AK yang belum mengajukan proses akreditasi.

Tabel 1. Data Penyelenggara Prodi Teologi \& PAK

Terakreditasi \& Proses Akreditasi BAN-PT

\begin{tabular}{|c|c|c|c|}
\hline \multirow{2}{*}{\multicolumn{1}{c|}{ Program Studi }} & \multicolumn{3}{|c|}{ Jumlah Penyelenggara Prodi } \\
\cline { 2 - 4 } & Terakreditasi & $\begin{array}{c}\text { Proses } \\
\text { Akreditasi }\end{array}$ & Jumlah \\
\hline S1 Pendidikan Agama Kristen & 50 & 109 & 159 \\
\hline S1 Teologi/ Kependetaan & 103 & 151 & 254 \\
\hline
\end{tabular}

Sumber: Data Sekunder, ban-pt.kemdiknas.go.id. 2014.

STT Simpson merupakan salah satu Lembaga Pendidikan Tinggi Teologi swasta yang dikelola oleh BPP Gereja Kemah Injil Indonesia. Sebagai organisasi publik seharusnya STT Simpson menjadi Perguruan Tinggi yang berkualitas sehingga dapat meningkatkan daya saing. Sebagai lembaga pendidikan teologi, STT Simpson diharapkan menyelenggarakan pendidikan teologi injili yang berkualitas dan mempersiapkan tenaga yang terampil dalam pelayanan di gereja dan masyarakat. STT Simpson mengelola dua program studi (Prodi) yaitu Prodi S-1 Teologi Kependetaan dan Prodi S-1 PAK yang dijalankan berdasarkan ijin operasional pada Kementrian Agama Cq. Direktur Jenderal Bimbingan Masyarakat Kristen dan memperoleh akreditasi $\mathrm{C}$ dari BAN-PT.

Dengan jumlah STT/AK yang cukup banyak menjadikan persaingan antar STT/AK menjadi semakin ketat. Karena ketatnya persaingan dan disertai dengan 
bertambahnya STT-STT baru, akhirnya berdampak pada jumlah penurunan pendaftar mahasiswa baru. Padalah salah satu unsur penting dalam pendidikan adalah input atau mahasiswa. Jumlah pendaftar merupakan salah satu indikator apakah sekolah mampu meraih perhatian pelanggan dan bersaing dengan sekolah lain. Pendaftaran mahasiswa baru akan mempengaruhi kelanjutan sebuah lembaga pendidikan. Di tengah persaingan antar sekolah yang semakin ketat apabila sekolah tidak memiliki mahasiswa maka kegiatan pendidikan di sekolah akan terhenti sebab mahasiswa merupakan input dan unsur inti dari perguruan tinggi (Pidarta 2011).

Persoalan rendahnya mahasiswa baru akibat persaiangan juga terjadi di STT Simpson, Pendaftaran mahasiswa baru dalam lima tahun ajaran terakhir pada kedua prodi di STT Simpson mengalami pasang surut sebagaimana tergambar dalam Gambar 1 di bawah ini, Hal itu tentu mempengaruhi pelaksanaan pendidikan di STT tersebut. Khotimah (2012) mengungkapkan bahwa jika terjadi penurunan jumlah pendaftar maka akan mempengaruhi pembiayaan sekolah dan proses belajar mengajar. Kondisi yang seperti itu akhirnya akan membahayakan kelangsungan sekolah.

Gambar 1. Grafik Penerimaan Mahasiswa Baru STT Simpson Ungaran

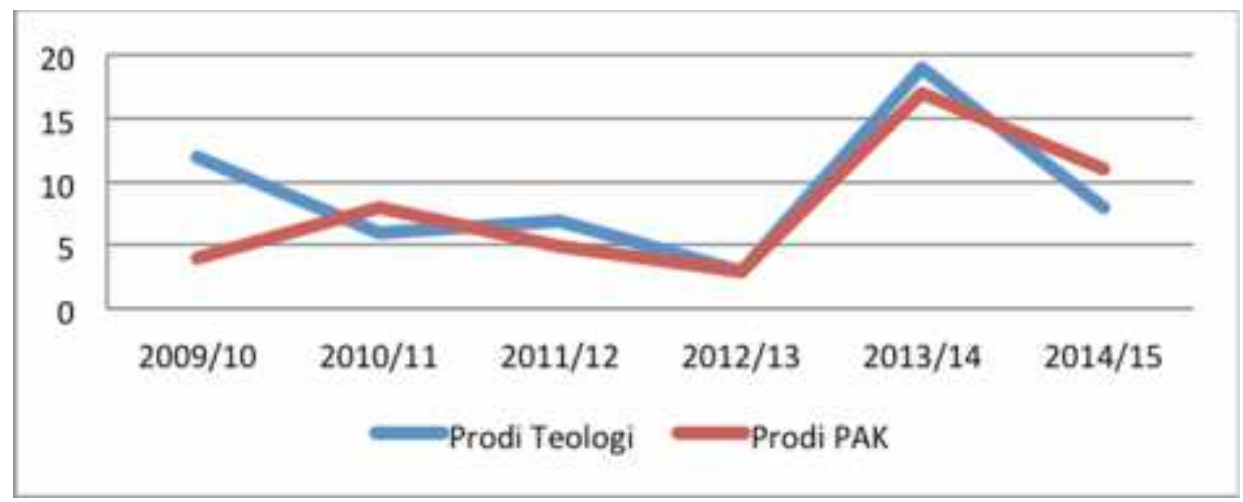

Sumber: Data Sekolah, 2014.

Untuk itu perlu sebuah strategi bersaing yang akan meningkatkan daya saing dan menjadikan STT Simpson memiliki daya tarik serta diminati oleh banyak calon mahasiswa. Usaha untuk memperoleh mahasiswa baru dengan hanya mengandalkan brosur dan spanduk tidak sepenuhnya akan menolong, dibutuhkan sebuah strategi yang baik untuk mempertahankan dan meningkatkan jumlah pelanggan dalam hal ini mahasiswa sebagai pelanggan dalam bidang pendidikan (Mulyono 2010, Sunyoto 2012). Dengan perkataan lain, agar dapat tetap bersaing dengan STT lainnya dan meningkatkan daya saing diperlukan sebuah strategi bersaing yang baik. Strategi menurut Sagala (2013) merupakan instrumen manajemen termasuk dalam manajemen sekolah. Sementara strategi bersaing menurut Porter (dlm. Bangun 2008) adalah pencarian posisi bersaing yang menguntungkan di arena bersaing dan untuk menentukan posisi menguntungkan dari kekuatan-kekuatan pesaing. Sementara tujuan akhir strategi bersaing menurut Kuntjoroadi \& Safitri (2009) adalah untuk menanggulangi kekuatan lingkungan demi kepentingan perusahaan.

Salah satu cara meningkatkan daya saing adalah peningkatan kualitas secara terus menerus dan terencana dengan baik sehingga proses peningkatan mutu dapat berjalan secara berkesinambungan dan mencapai hasil seperti menjadi daya tarik 
bagi pengguna jasa pendidikan dan kebanggaan bagi mahasiswanya (Syafaruddin 2012, Sallis 2012).

Daya saing adalah gambaran bagaimana sebuah organisasi dan SDM-nya mengendalikan kekuatan kompetensi yang dimilikinya dengan terpadu hingga memperoleh keuntungan (Zuhal 2010), sementara Thoha (2004) menjelaskan bahwa daya saing merupakan salah satu cara untuk memenangkan kompetisi sebuah organisasi. Jadi daya saing merupakan sebuah cara dengan melibatkan seluruh aspek dalam organisasi untuk memperoleh keuntungan dan memenangkan kompetisi. Hubeis \& Najib (2014) mengambarkan situasi saat ini dimana semakin banyaknya alternatif yang ditawarkan dalam segala bidang termasuk pendidikan mendorong adanya upaya peningkatan daya saing bahkan hingga ke level superior competitive advantage.

Bagi lembaga pendidikan upaya meningkatkan daya saing merupakan hal yang penting dan menjadi keharusan agar dapat menjalankan penyelenggaraan pendidikan secara berkesinambungan. Dalam pemarasan sekolah dan meningkatkan daya saing sekolah Hidayat dan Machali (2012) mengemukakan langkah-langkah strategi bersaing yang perlu diperhatikan yaitu:

a. Identifikasi Pasar

Pada bagian ini sekolah harus melakukan penelitian untuk mengetahui kondisi dan ekspektasi pasar termasuk atribut-atribut pendidikan yang menjadi kepentingan pelanggan. Dalam sisi marketing STT merupakan pemberi jasa pendidikan yang segmen pasarnya mulai bergeser dari segmen emosional ke segmen rasional. Pada segmen emosional pelanggan lebih memperhatikan religiusitas serta kurang memperhatikan harga, kualitas, mutu dan ketersediaan jaringan yang memadai sementara segmen rasional, pelanggan benar-benar sensitif terhadap perkembangan kualitas dan mutu pendidikan (Hidayat \& Machali 2012).

b. Segmentasi Pasar

Segmentasi pasar adalah membagi pasar menjadi kelompok pembeli yang dibedakan berdasarkan kebutuhan, karakteristik, atau tingkah laku, yang mungkin membutuhkan produk yang berbeda (Hidayat \& Machali 2012). Porter (1997) menjelaskan bahwa mungkin saja produk atau jasa yang dikehendaki ada di tempat lain tetapi mungkin saja terdapat segmen-segmen dalam pasar yang belum terlayani dengan baik, sehingga untuk meningkatkan daya saing strategi ini perlu diperhatikan dengan melihat apakah ada segmen pasar yang masih belum digarap oleh yang lain.

\section{c. Diferensiasi}

Hidayat \& Machali (2012) menjelaskan bahwa diferensiasi merupakan satu dari tiga strategi pemasaran sebagai strategi bersaing. Dengan diferensiasi sekolah dapat memberikan penawaran yang berbeda dengan penawaran yang diberikan oleh sekolah lain. Sehingga sekolah dituntut untuk memberikan penawaran atribut dan jasa yang berbeda dengan pesaing lainnya serta menyediakan nilai-nilai unik dan superior kepada pelanggan dari sisi kualitas atau ciri khusus (Jubelina \& Supramono 2013, Hidayat \& Machali 2012, Hunger \& Wheelen 2003). Pada langkah ini strategi 
dapat dilakukan dengan memberikan citra yang baik sehingga meningkatkan daya saing. Selain diferensiasi dua strategi pemasaran sebagai strategi bersaing lainnya adalah keunggulan biaya (low cost) yang mengefisienkan seluruh biaya produksi sehingga menghasilkan jasa yang dapat dijual lebih murah dari pesaing dan fokus (focus) yang menggarap pasar khusus atau memilih kelompok tertentu, biasanya dilakukan pada jasa yang memiliki karakteristik khusus (Hidayat \& Machali 2012, Jubelina \& Supramono 2013).

\section{d. Komunikasi Pemasaran}

Konsumen terkadang tidak menyadari bahkan mungkin benar-benar tidak mengetahui keberadaan sebuah produk atau jasa yang ditawarkan. Melalui komunikasi, konsumen dapat menyadari dan memahami keberadaan produk atau jasa yang ditawarkan. Bentuk komunikasi yang dapat dilakukan seperti penyelenggaraan kompetisi, forum ilmiah, publikasi prestasi di media masa, atau bahkan dalam bentuk promosi secara langsung. Hidayat dan Machali (2012) mengungkapkan bahwa komunikasi yang sering dilupakan adalah komunikasi dari mulut ke mulut. Sebagai contoh alumni satu sekolah menyampaikan tentang pengalaman di sekolah dan keberhasilan sekolahnya.

e. Pelayanan Sekolah

Pelayanan merupakan sebuah tolok ukur yang sering dilihat oleh pelanggan. Berkaitan dengan pelayanan, yang harus diperhatikan adalah keandalan untuk melaksanakan jasa yang dijanjikan dengan tepat dan terpercaya, responsip dalam membantu pelanggan dan memberikan jasa, pengetahuan dan kompetensi dosen untuk menimbulkan kepercayaan, menaruh empati pada pelanggan seperti dengan menaruh perhatian pada perkembangan mahasiswa, menampilkan fasilitas fisik yang lengkap dan baik (Hidayat \& Machali 2012). Karena pendidikan merupakan sebuah proses yang harus terus berjalan dan berkaitan secara terus menerus dengan pelanggan, maka sekolah sebagai penyedia jasa pendidikan perlu belajar dan memiliki inisiatif untuk meningkatkan kepuasan pelanggan pada pelayanan sekolah (Wijaya 2008). Pelayanan yang baik akan memberikan kepuasan bagi pelanggan serta akan membangun daya tarik pelanggan.

Dari latar belakang masalah di atas maka rumusan masalah yang diangkat dalam penelitian ini adalah apa yang menjadi strategi bersaing yang dapat meningkatkan daya saing STT Simpson? Dari rumusan masalah di atas maka tujuan dari penelitian ini adalah merancang sebuah strategi bersaing untuk meningkatkan daya saing STT Simpson.

\section{METODE}

Jenis penelitian ini adalah penelitian deskriptif kualitatif. Bogdan dan Biklen (1992 dlm. Rahmat 2009) menjelaskan bahwa jenis penelitian ini merupakan suatu prosedur penelitian yang menghasilkan data deskriptif berupa tulisan dan perilaku orang yang diamati. Proses penelitian ini dilaksanakan dengan mengajukan pertanyaan-pertanyaan, mengumpulkan data dari partisipan, menganalisi data dan menafsirkan data sehingga data yang dihasilkan adalah kata-kata, gambar, dan bukan 
angka-angka (Creswell 2013, Moleong 2010). Penelitian ini dilakukan di STT Simpson.

Dalam mengumpulkan data, peneliti melakukan observasi partisipatif untuk memperoleh gambaran awal dan keadaan sekolah. Kemudian peneliti melakukan beberapa kali FGD dengan melibatkan Unsur Pimpinan, Kaprodi, Perwakilan Dosen, Tenaga Kependidikan dan Perwakilan Mahasiswa. Data dari hasil FGD peneliti akan divalidasi dengan melakukan wawancara terhadap dosen, mahasiswa, dan dari mitra STT yang tidak terlibat dalam FGD. Langkah-langkah analisis dalam penelitian ini adalah data reduction, data display, dan conclusion drawing. Dalam penelitian ini dilakukan uji kredibilitas untuk mengetahui apakah semua data yang diperoleh dari hasil FGD, Wawancara dan Observasi sudah valid dan reliabel. Untuk memperoleh data yang lebih akurat, mendalam dan dapat dipercaya maka dilakukan perpanjangan pengamatan, trianggulasi yang memanfaatkan penggunaan sumber dan metode, serta dilakukan pemeriksaan sejawat.

\section{HASIL PENELITIAN}

Data yang diperoleh dan dianalisis dalam penelitian ini diperoleh melalui Focus Group Discussion (FGD) yang dilakukan pada 12, 18 September 2014 dan 14 Oktober 2014. Dalam FGD tersebut hadir Ketua STT, Pembantu Ketua (Puket), Kaprodi Teologi dan PAK, perwakilan Tenaga Kependidikan, dan Mahasiswa. Dalam FGD tersebut peneliti melakukan sesi brainstorming untuk mengidentifikasi faktor strategis internal yaitu kekuatan dan kelemahan, serta faktor strategis eksternal yaitu peluang dan ancam.

Hasil FGD untuk faktor strategis internal yaitu kekuatan dan kelemahan maka diperoleh matriks IFAS (Tabel 2) dan hasil FGD untuk faktor strategis eksternal yaitu peluang dan ancaman maka diperoleh matriks EFAS (Tabel 4.6). Berikut hasil analisis faktor kekuatan dan kelemahan:

Tabel 2. Matriks IFAS

\begin{tabular}{|c|c|c|c|c|}
\hline No & KEKUATAN & Bobot & Rating & $\begin{array}{c}\text { Bobot } x \\
\text { Rating }\end{array}$ \\
\hline 1. & Perpustakaan yang memadai. & 0,20 & 4 & 0,80 \\
\hline 2. & $\begin{array}{l}\text { Ciri khas STT Simpson yang menekankan pembentukan } \\
\text { karakter. }\end{array}$ & 0,20 & 4 & 0,80 \\
\hline 3. & Berada dalam naungan BPP GKII & 0,15 & 4 & 0,60 \\
\hline 4. & Memiliki Pasar yang pasti di beberapa daerah dan GKII. & 0,15 & 3 & 0,45 \\
\hline 5. & Alumni tersebar diberbagai tempat & 5 & 3 & 45 \\
\hline 6. & Sarana $\mathrm{p}$ & 0,10 & 3 & 0,30 \\
\hline 7. & $\begin{array}{l}\text { Biaya Kuliah dan Akomodasi di STT Simpson tergolong } \\
\text { murah. }\end{array}$ & 0,05 & 2 & 0,10 \\
\hline & $\begin{array}{ll}\text { Total Skor } \\
\end{array}$ & 1 & & 3,50 \\
\hline No & KELEMAHAN & Bobot & Rating & $\begin{array}{l}\text { Bobot } x \\
\text { Rating }\end{array}$ \\
\hline 1. & Akreditasi Kedua Prodi Masih C & 0,2 & 1 & 0,25 \\
\hline 2. & Penggunaan teknologi yang belum menyeluruh. & 0,2 & 2 & 0,40 \\
\hline 3. & $\begin{array}{l}\text { GKII memiliki } 13 \text { STT yang tersebar di beberapa daerah } \\
\text { di Indonesia }\end{array}$ & 0,15 & 3 & 0,45 \\
\hline 4. & Komunikasi antara STT dengan gereja-gereja yang kurang & 0,15 & 1 & 0,15 \\
\hline
\end{tabular}




\begin{tabular}{|c|c|c|c|c|}
\hline 5. & Tempat kurang strategis & 0,15 & 3 & 0,45 \\
\hline 6. & Sistem Informasi Manual & 0,1 & 2 & 0,20 \\
\hline \multirow{2}{*}{\multicolumn{4}{|c|}{ Total skor akhir (Kekuatan - Kelemahan) }} & 1,90 \\
\hline & & & & 1,60 \\
\hline
\end{tabular}

Sumber: Hasil FGD, 2014

Dari hasil perhitungan Matriks IFAS di atas maka diperoleh total skor akhir untuk Kekuatan - Kelemahan adalah 1,90.

Hasil dari FGD yang penulis lakukan bersama dengan Unsur Pimpinan, Kaprodi, Perwakilan Dosen, Tenaga Kependidikan dan Perwakilan Mahasiswa untuk faktor strategis eksternal yaitu peluang dan ancaman maka diperoleh matriks EFAS dalam Tabel 3 berikut:

Tabel 3. Matriks EFAS

\begin{tabular}{|l|l|c|c|c|}
\hline No & \multicolumn{1}{|c|}{ PELUANG } & Bobot & Rating & $\begin{array}{c}\text { Bobot x } \\
\text { Rating }\end{array}$ \\
\hline 1. & $\begin{array}{l}\text { Kebutuhan tenaga/pengerja di lingkungan gereja/para } \\
\text { gereja. }\end{array}$ & 0,25 & 4 & 1 \\
\hline 2. & Jumlah pemuda gereja yang besar & 0,20 & 4 & 0,80 \\
\hline 3. & $\begin{array}{l}\text { Lulusan dapat diterima gereja dan lembaga } \\
\text { pemerintahan/swasta. }\end{array}$ & 0,20 & 4 & 0,80 \\
\hline 4. & $\begin{array}{l}\text { Belum adanya kelas malam untuk pendidikan teologi di } \\
\text { Ungaran. }\end{array}$ & 0,15 & 4 & 0,60 \\
\hline 5. & Teknologi yang berkembang. & 0,20 & 3 & 0,60 \\
\hline & \multicolumn{1}{|c|}{ Total Skor } & 1 & & 3,80 \\
\hline No & \multicolumn{1}{|c|}{ Bobot } & Rating & $\begin{array}{l}\text { Bobot x } \\
\text { Rating }\end{array}$ \\
\hline 1. & $\begin{array}{l}\text { STT-STT baru yang memberi beasiswa penuh bagi } \\
\text { mahasiswanya. }\end{array}$ & 0,25 & 1 & 0,25 \\
\hline 2. & Gereja-gereja yang memiliki STT sendiri. & 0,25 & 2 & 0,50 \\
\hline 3. & Rendahnya minat kuliah di sekolah Teologi. & 0,20 & 1 & 0,20 \\
\hline 4. & Ada STT di luar GKII yang menggarap pasar GKII. & 0,20 & 3 & 0,60 \\
\hline 5. & $\begin{array}{l}\text { Meningkatnya peraturan pemerintah terkait } \\
\text { penyelenggaraan PT. }\end{array}$ & 0,10 & 2 & 0,20 \\
\hline & \multicolumn{1}{|c|}{ Total Skor } & 1 & & 1,75 \\
\hline & \multicolumn{1}{|c|}{ Total skor akhir (Peluang-Ancaman) } & 2,05 \\
\hline
\end{tabular}

Sumber: Hasil FGD, 2014

Total bobot dikali rating untuk peluang adalah 3,80. Total bobot dikali rating untuk ancaman adalah 1,75. Dari hasil perhitungan Matriks EFAS maka diperoleh Total skor akhir untuk Peluang - Ancaman adalah 2,05.

Perhitungan total skor yang diperoleh setelah melakukan identifikasi terhadap faktor strategis internal yaitu kekuatan dan kelemahan, dan faktor strategis eksternal yaitu peluang dan ancaman adalah:

Tabel 4. Skor Akhir IFAS dan EFAS

\begin{tabular}{|c|c|c|c|}
\hline Kategori & Skor & Kategori & Skor \\
\hline Kekuatan $(\mathrm{S})$ & 3,50 & Peluang $(\mathrm{O})$ & 3,80 \\
\hline Kelemahan $(\mathrm{W})$ & 1,90 & Ancaman $(\mathrm{T})$ & 1,75 \\
\hline Total S - W & 1,60 & Total O - T & 2,05 \\
\hline \multicolumn{4}{|c}{170}
\end{tabular}


Dari hasil perhitungan skor akhir matriks IFAS maka diperoleh skor akhir IFAS adalah 1,60. Sementara dari hasil perhitungan skor akhir matriks EFAS maka diperoleh skor akhir EFAS adalah 2,05. Berdasarkan hasil perhitungan IFAS dan EFAS maka strategi berada pada kuadran S-O. Pada kuadran S-O, sekolah membangun daya saing dengan menangkap peluang yang ada menggunakan kekuatan yang dimiliki.

Adapun strategi untuk meningkatkan daya saing STT Simpson berdasarkan analisis SWOT adalah strategi agresif.

Tabel 5. Matriks Analisis SWOT

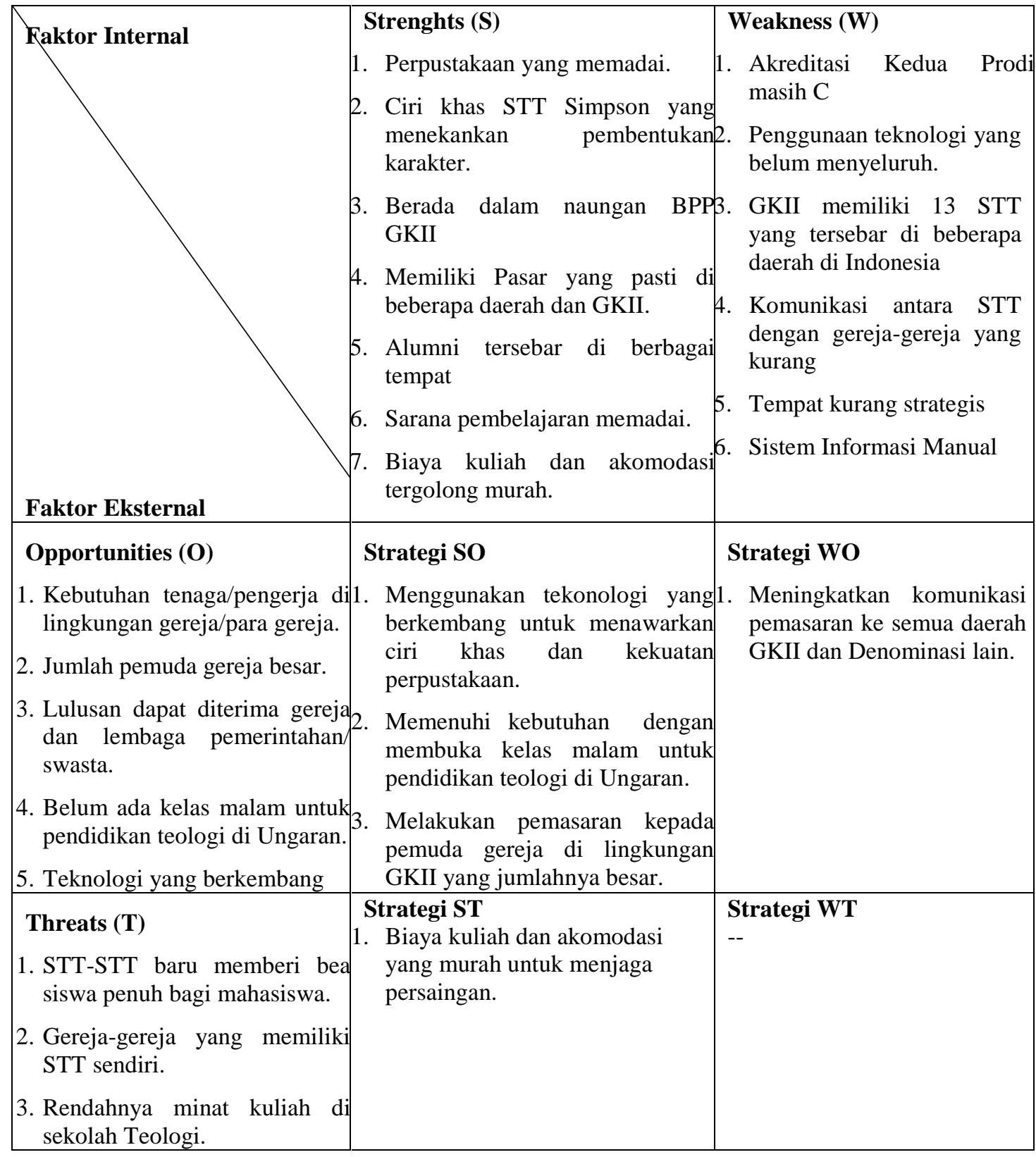


4. Ada STT di luar GKII yang menggarap pasar GKII.

5. Meningkatnya peraturan peme rintah terkait penyelenggaraan PT.

Berdasarkan analisis SWOT tersebut maka strategi untuk meningkatkan daya saing STT Simpson adalah:

1) Menggunakan tekonologi yang berkembang untuk menawarkan ciri khas dan kekuatan perpustakaan.

2) Memenuhi kebutuhan pengerja dengan membuka kelas malam untuk pendidikan teologi di Ungaran memanfaatkan sarana yang dimiliki.

3) Melakukan pemasaran kepada pemuda gereja di lingkungan GKII yang jumlahnya besar.

4) Biaya Kuliah dan Akomodasi yang murah untuk menjaga persaingan.

5) Meningkatkan komunikasi pemasaran ke semua daerah GKII dan Denominasi lain.

\section{PEMBAHASAN}

Kelima strategi tersebut di atas penulis akan uraikan dalam langkah strategi bersaing berikut yaitu: Deferensiasi, Keunggulan Biaya, Fokus, dan Komunikasi Pemasaran.

\section{Deferensiasi}

Berdasarkan analisis SWOT, STT Simpson memiliki beberapa kekuatan dan peluang yang dapat dimanfaatkan sebagai strategi bersaing. Dalam matriks analisis SWOT terdapat strategi SO yang dapat menjadi strategi deferensiasi yaitu: Memenuhi kebutuhan pengerja dengan membuka kelas malam untuk pendidikan teologi di Ungaran dengan memanfaatkan sarana yang dimiliki.

STT Simpson dapat menawarkan kelas malam untuk pendidikan teologi di Ungaran dengan memaksimalkan sarana yang dimiliki kepada gereja-gereja yang ada di Ungaran dan sekitarnya. Program kelas malam untuk pendidikan teologi dapat menjadi jasa yang berbeda dengan STT lainnya di Ungaran. Jasa yang berbeda ini dapat disertai dengan menyediakan nilai-nilai unik dan superior kepada pelanggan dari sisi ciri khusus yaitu penekanan karakter, Teologi Injili, dan keunggulan perpustakaan yang dimiliki.

Langkah strategi ini dibarengi dengan memberikan citra yang baik dengan melakukan komunikasi dan pencitraan yang positif. Komunikasi dan pencitraan yang positif dapat dibangun dengan berbagai bentuk komunikasi seperti penyelenggaraan kompetisi yang mengundang gereja-gereja, forum ilmiah atau seminar ilmiah, promosi secara langsung. Sementara untuk membangun citra positif, yang dilakukan adalah dengan melakukan publikasi prestasi di media masa cetak maupun online yang berkaitan langsung dengan gereja-gereja di Ungaran.

\section{Keunggulan Biaya}


Strategi keunggulan biaya dapat menjadi salah satu strategi STT Simpson. Strategi ini dapat menghadapi tantangan karena ada STT-STT lain yang menawarkan beasiswa penuh bagi para mahasiswanya. Dengan menawarkan biaya Kuliah dan Akomodasi yang bersaing untuk menjaga persaingan.

Tabel 6. Perbandingan Biaya Studi S1 Teologi dan PAK Tahun 2014

\begin{tabular}{|c|c|c|c|c|}
\hline \multirow[b]{2}{*}{ No } & \multirow[b]{2}{*}{ Jenis Biaya } & \multicolumn{3}{|c|}{ Biaya } \\
\hline & & $\begin{array}{l}\text { STT Jaffray } \\
\text { Makasar }\end{array}$ & $\begin{array}{l}\text { STT Jaffray } \\
\text { Jakarta }\end{array}$ & STT Simpson \\
\hline 1. & Formulir Masuk & 200.000 & 200.000 & 75.000 \\
\hline 2. & Tes masuk dan orientasi & 800.000 & 800.000 & \\
\hline 3. & Sumbangan pembangunan $(1 \mathrm{x})$ & 1.000 .000 & 2.000 .000 & 800.000 \\
\hline 4. & Penyelenggaraan pendidikan*) & - & 1.000 .000 & 380.000 \\
\hline 5. & Registrasi/Smt. & - & 300.000 & 200.000 \\
\hline 6. & Biaya Kuliah**) & 1.300 .000 & - & - \\
\hline 7. & Biaya Per SKS & - & 50.000 & 75.000 \\
\hline 8. & Jaket Almater (1x) & 175.000 & - & 200.000 \\
\hline 9. & Asrama/Smt.***) & 500.000 & - & 500.000 \\
\hline 10. & Konsumsi/Bulan & 750.000 & - & 300.000 \\
\hline \multicolumn{5}{|c|}{ Catatan: } \\
\hline $\begin{array}{l}*) \\
* *) \\
* * *)\end{array}$ & \multicolumn{4}{|c|}{$\begin{array}{l}\text { Biaya Perpustakaan, Laboratorium dan BEM/SEMA } \\
\text { STT Jaffray tidak mengunakan pembayaran berdasarkan sistem SKS tetapi } \\
\text { dengan sistem paket. } \\
\text { Mahasiswa STT Jaffray Jakarta tidak tinggal di Asrama. }\end{array}$} \\
\hline
\end{tabular}

Sumber: http://sttjaffrayjakarta.ac.id/, http://sttjaffray.ac.id/, http://sttsimpson.org/, 2014.

Berdasarkan data yang digambarkan dalam Tabel 6 tentang perbandingan biaya studi S1 Teologi dan PAK Tahun 2014, STT Simpson memiliki keunggulan dalam sumbangan pembangunan dan biaya konsumsi yang lebih murah dibandingkan dua STT GKII lainnya. Sementara biaya penyelenggaraan pendidikan dan biaya registrasi, STT Simpson lebih murah dibandingkan STT Jaffray Jakarta.

Dengan keunggulan biaya tersebut di atas, STT Simpson masih harus menyesuaikan biaya kuliah agar tidak tejadi kesenjangan yang terlalu jauh dengan STT lain dan tetap menjaga daya saing. Biaya yang harus disesuaikan adalah biaya penyelenggaraan pendidikan, registrasi/smt., dan biaya kuliah (SKS). Berdasarkan data dalam Tabel 6, STT Jaffray Makasar menggabungkan ketiga jenis biaya tersebut menjadi satu yaitu biaya kuliah sebesar Rp 1.300.000/smt.. Sementara STT Jaffray Jakarta dan STT Simpson membaginya sesuai tiga jenis tersebut. Jika dihitung penggabungan dari tiga jenis tersebut biaya kuliah STT Simpson masih jauh lebih mahal dibandingkan STT Jaffray Makasar tetapi masih lebih murah dibandingkan STT Jaffray Jakarta. Jika mahasiswa STT Simpson mengambil 20 SKS/smt. X Rp 75.000 maka total biayanya Rp 1.500.000. Sementara jika mahasiswa STT Jaffray Jakarta mengambil $20 \mathrm{SKS} / \mathrm{smt}$. X Rp 50.000 maka total biayanya Rp 1.000.000. Total dari penggabungan tiga jenis biaya kuliah digambarkan dalam Tabel 7 berikut:

Tabel 7. Perbandingan Biaya Kuliah

\begin{tabular}{|c|c|c|c|}
\hline Jenis biaya & $\begin{array}{c}\text { STT Jaffray } \\
\text { Makasar }\end{array}$ & $\begin{array}{c}\text { STT Jaffray } \\
\text { Jakarta }\end{array}$ & $\begin{array}{c}\text { STT } \\
\text { Simpson }\end{array}$ \\
\hline
\end{tabular}




\begin{tabular}{|r|r|r|r|}
\hline Penyelenggaraan pendidikan & & 1.000 .000 & 380.000 \\
\hline Registrasi/Smt. & & 300.000 & 200.000 \\
\hline Total Biaya SKS & & 1.000 .000 & 1.500 .000 \\
\hline Total & 1.300 .000 & 2.300 .000 & 2.080 .000 \\
\hline
\end{tabular}

Melihat Tabel 7 perbandingan biaya kuliah, STT Jaffray Makasar yang menggabungkan tiga jenis biaya tersebut maka biaya kuliahnya lebih murah dibandingkan STT Simpson dan STT Jaffray Jakarta. Tetapi biaya kuliah STT Simpson masih lebih murah dibandingkan STT Jaffray Jakarta. Untuk tetap dapat menjaga daya saing terhadap STT lain, STT Simpson harus menyesuaikan tiga jenis biaya kuliah tersebut.

\section{Fokus}

STT Simpson membangun daya saingnya dengan menggunakan Strategi SO dalam matriks analisis SWOT yaitu: Melakukan pemasaran kepada pemuda gereja di lingkungan GKII yang jumlahnya besar.

Gambar 2. Strategi Fokus

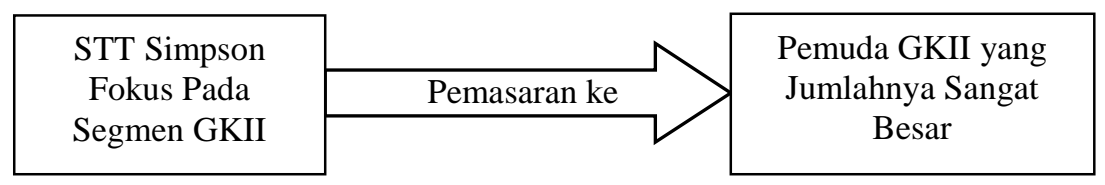

STT Simpson membangun strategi bersaingnya dengan fokus pada segmen pasar GKII. Dalam hal ini STT Simpson fokus menggarap pasar GKII karena:

a. Jumlah pemuda GKII sangat besar. Jumlah pemuda yang besar dapat menjadi pasar yang potensial. Potensi ini dapat menjadi fokus pemasaran STT Simpson.

b. STT Simpson juga memiliki kekuatan untuk fokus menggarap pasar GKII karena STT Simpson berada dalam naungan BPP GKII. Dengan berada dalam naungan BPP GKII, STT Simpson dapat melakukan pemasaran di semua daerah GKII sehingga STT Simpson dapat fokus pemasaran pada segmen ini.

c. Jika menggarap pasar gereja lain, denominasi gereja-gereja lain telah memiliki STT sendiri.

\section{Komunikasi Pemasaran}

STT Simpson dapat memanfaatkan strategi WO dalam matriks analisis SWOT untuk melakukan komunikasi pemasaran yaitu dengan meningkatkan komunikasi pemasaran ke semua daerah GKII dan Denominasi lain. Serta strategi SO yaitu strategi yang menggunakan tekonologi yang berkembang untuk menawarkan ciri khas dan kekuatan perpustakaan.

STT Simpson dapat meningkatkan komunikasi pemasaran dengan memanfaatkan teknologi yang berkembang yang menawarkan ciri khas yang dimiliki yaitu penekanan pada pembentukan karakter dan menawarkan perpustakaan yang memadai. Ciri khas yang menekankan pada pembentukan karakter sejalan dengan 
visi STT Simpson dapat menjadi keunikan yang ditawarkan kepada pengguna jasa. Sementara berdasarkan hasil FGD yang penulis lakukan diketahui bahwa perpustakaan STT Simpson adalah perpustakaan nomor 2 terbesar di bawah perpustakaan STT Jaffray Makasar. Sementara dari 3 STT yang ada di Ungaran, perpustakaan STT Simpson tidak hanya dikunjungi oleh mahasiswa STT Simpson saja melainkan dikunjungi oleh mahasiswa dari dua STT lainnya. STT Simpson dapat mengomunikasikan kedua kekuatan tersebut dengan menggunakan berbagai bentuk komunikasi pemasaran.

Gambar 3. Strategi Komunikasi Pemasaran

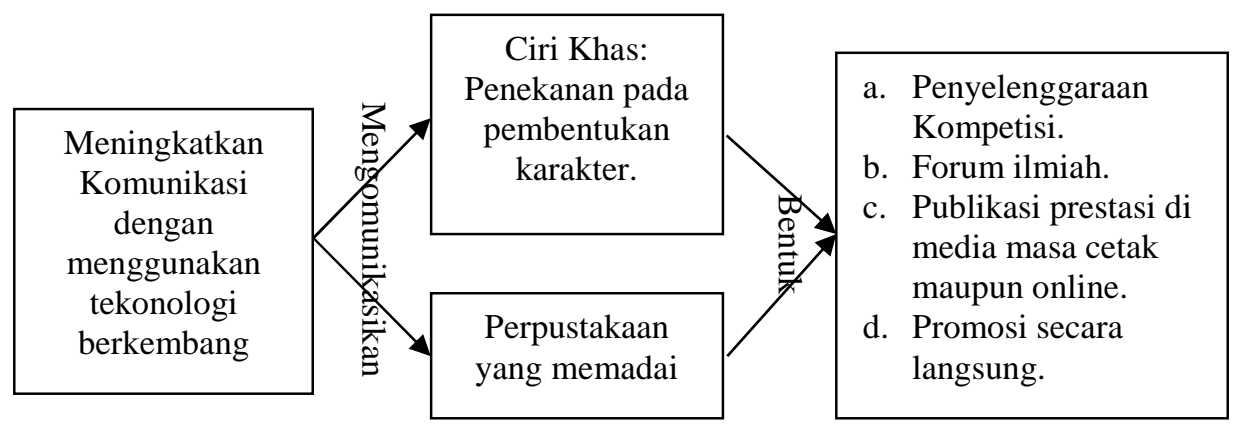

Bentuk komunikasi pemasaran yang dapat dibuat oleh STT Simpson adalah:

a. Penyelenggaraan Kompetisi seperti lomba karya tulis ilmiah untuk pendidikan SMA/SMTK, Lomba Paduan Suara Gerejawi, Cerdas Cermat Alkitab.

b. Forum ilmiah seperti diskusi ilmiah guru-guru, diskusi pelayanan gerejawi.

c. Publikasi prestasi di media masa cetak maupun online.

d. Promosi secara langsung.

\section{SIMPULAN DAN SARAN}

\section{Simpulan}

Dari uraian di atas dapat disimpulkan bahwa strategi bersaing untuk STT Simpson adalah sebagai berikut:

1) pada strategi diferensiasi, STT Simpson dapat menawarkan kelas malam untuk pendidikan teologi di Ungaran dengan memaksimalkan sarana yang dimiliki kepada gereja-gereja yang ada di Ungaran dan sekitarnya.

2) pada strategi keunggulan biaya, STT Simpson memiliki keunggulan dalam sumbangan pembangunan, biaya konsumsi yang lebih murah dibandingkan dua STT GKII lainnya. Sementara biaya penyelenggaraan pendidikan dan biaya registrasi, STT Simpson lebih murah dibandingkan STT Jaffray Jakarta. Tetapi STT Simpson masih harus menyesuaikan biaya kuliah agar tidak tejadi kesenjangan yang terlalu jauh dengan STT lain dan tetap menjaga daya saing.

3) pada strategi fokus, STT Simpson fokus melakukan pemasaran kepada pemuda gereja di lingkungan GKII. 
4) strategi bersaing berikutnya adalah komunikasi pemasaran, STT Simpson dapat meningkatkan komunikasi pemasaran dengan memanfaatkan teknologi yang berkembang yang menawarkan ciri khas yang dimiliki. Saran

Sejalan dengan hasil penelitian di atas maka kepada STT Simpson Ungaran disarankan agar menerapkan berbagai strategi sebagaimana telah dikaji di atas, yang meliputi strategi diferensiasi, strategi keunggulan biaya, strategi fokus kepada pelanggan dan strategi komunikasi pemasaran.

\section{DAFTAR PUSTAKA}

Bangun, W. 2008. "Budaya Organisasi: Dampaknya Pada Peningkatan Daya Saing Perusahaan". Jurnal Manajemen, Vol.8, No.1, November 2008.

Creswell, J.W. 2013. Research Design: Pendekatan Kualitatif, Kuantitatif, dan Mixed. Yogyakarta: Pustaka Pelajar.

Direktori BAN-PT. http://ban-pt.kemdiknas.go.id. Diakses pada 02 Mei 2014.

Hidayat, A. \& Machali, I. 2012. Pengelolaan Pendidikan. Yogyakarta: Kaukaba.

Hubeis, M. \& Najib, M. 2014. Manajemen Strategik Dalam Pengembangan Daya Saing Organisasi. Jakarta: Elex Media Komputindo.

Hunger, J.D. \& Wheelen, T.L. 2003. Manajemen Strategis. Yogyakarta: Penerbit Andi.

Jubelina \& Supramono. 2013. "Strategi Bersaing Sekolah Kristen Lentera Ambarawa". Satya Widya: Jurnal Penelitian Pengembangan Pendidikan, Vol. 29, No. 2, Desember 2013.

Khotimah, S. 2012. "Perumusan Strategi Bagi Perguruan Tinggi Swasta (PTS) Untuk Meraih Keunggulan Bersaing (Studi Kasus Pada Universitas Merdeka Malang)". Jurnal SPREAD, April 2012, Volume 2, Nomor 1.

Kuntjoroadi, W. \& Safitri, N. 2009. "Analisis Strategi Bersaing dalam Persaingan Usaha Penerbangan Komersial”. Bisnis \& Birokrasi, Jurnal Ilmu Administrasi dan Organisasi, Jan - Apr 2009, Volume 16, Nomor 1.

Moleong, L.J. 2010. Metode Penelitian Kualitatif. Bandung: Remaja Rosdakarya.

Mulyono. 2010. Manajemen Administrasi dan Organisasi Pendidikan. Yogyakarta: Ar-Ruzz Media.

Peraturan Pemerintah No. 55 Tahun 2007 tentang Pendidikan Agama Dan Pendidikan Keagamaan. Jakarta: Depdiknas

Pidarta, M. 2011. Manajemen Pendidikan Indonesia. Jakarta: Rineka Cipta.

Porter, Michael E. 1997. Strategi Bersaing, Teknik Menganalisis Industri Dan Pesaing. Jakarta: Erlangga.

Rahmat, P.S. 2009. "Penelitian Kualitatif”. Jurnal Equilibrium. Vol. 5, No. 9, Januari - Juni 2009. 
Sagala, S. 2013. Manajemen Strategik Dalam Peningkatan Mutu Pendidikan. Bandung: Alfabeta.

Sallis, E. 2012. Total Quality Management in Education. Terj. Yogyakarta: IRCiSoD.

Sunyoto, D. 2012. Konsep Dasar Riset Pemasaran \& Perilaku Konsumen. Yogyakarta: CAPS.

Syafaruddin. 2012. Pendidikan dan Pemberdayaan Masyarakat. Medan: Perdana Publishing.

Thoha, M. 2004. Strategi Peningkatan Daya Saing Industri Makanan Olahan Indonesia Dalam Era Globalisasi. Jakarta: LIPI. http://books.google.co.id. Diakses pada 30 Mei 2014.

Wijaya, D. 2008. "Pemasaran Jasa Pendidikan Sebagai Upaya untuk Meningkatkan Daya Saing Sekolah". Jurnal Pendidikan Penabur, No.11, Tahun ke-7, Desember 2008.

Zuhal. 2010. Knowledge and Innovation Platform Kekuatan Daya Saing. Jakarta: Gramedia. 